\title{
Do farm audits improve milk quality?
}

\author{
A. Flores-Miyamoto, ${ }^{*} †$ M. W. Reij, ${ }^{* 1}$ and A. G. J. Velthuis $† \ddagger$ \\ *Laboratory of Food Microbiology, Wageningen University, PO Box 17, 6700 AA, Wageningen, the Netherlands \\ †Business Economics, Wageningen University, Hollandseweg 1, $6706 \mathrm{KN}$, Wageningen, the Netherlands \\ fGD Animal Health Service, PO Box 9, 7400 AA, Deventer, the Netherlands
}

\begin{abstract}
Milk quality is assessed using bulk milk analysis and by farm audits in the Netherlands. However, the extent of the effect that dairy farm audits have on milk quality is unknown. Data from over 13,000 audits performed on 12,855 dairy farms from February 2006 to April 2008 were merged with laboratory test results of 325,150 bulk milk samples collected 6 mo before and after the audit. A linear mixed model with the method of restricted maximum likelihood was conducted to study whether the total bacterial counts (TBC) of bulk milk were lower during the periods before and after the dairy farm audit. Results showed that TBC values were 2 to $6 \%$ lower (i.e., 0.010 to $0.026 \log \mathrm{cfu} / \mathrm{mL}$ ) for a period from 1.5 to at least 6 mo after an audit. Additionally, several variables were significantly associated with bulk milk TBC values: seasonality, total number of attention points (given if some checklist points were not appropriate), audit type, audit result, and the categories milking equipment maintenance, and utility room-tank maintenance. The TBC values increased with a higher level of attention points. Furthermore, the farms rejected based on the audit results had the highest average TBC values and the approved farms had the lowest values. If dairy farms had an overall negative audit assessment and consequently needed a re-audit in the following year, the TBC values of bulk milk were more likely to be higher. Auditing may provide dairy farmers the opportunity to receive advice about factors that influence bulk milk TBC values, for a period of at least 6 mo following the audit.
\end{abstract}

Key words: bulk milk, certification scheme, secondparty audit, hygiene

\section{INTRODUCTION}

Over the past few years, the quality and safety of dairy products have become an increasing issue of concern for both consumers and producers. This is due,

\footnotetext{
Received October 4, 2012.

Accepted August 26, 2013.

${ }^{1}$ Corresponding author: martine.reij@wur.nl
}

in part, to incidents such as dioxin contamination of animal feed in Belgium (Boor, 2001; Noordhuizen and Metz, 2005) and Germany (Velthuis and Van Asseldonk, 2011), melamine-contaminated powdered infant formula in China (Haenlein, 2002; WHO, 2008), and outbreaks of Escherichia coli O104:H4 infection in 16 countries in Europe and North America (EFSA, 2010). Today, the food industry is under the watchful eye of many; consumers are concerned and demanding information about the quality and safety of products and on how they are produced (Hutchison et al., 2005; Gonzalo et al., 2006). Losses can be considerable for food business operators if the quality and safety of the product is insufficient or if the product is recalled (Velthuis et al., 2009; Velthuis and Van Asseldonk, 2011). This is one reason for the food processing industry to set high standards for quality and safety criteria. Microbiological contamination of milk is an important issue because pathogens can affect food safety, and spoilage microorganisms can limit shelf life and affect quality or yield of milk products.

The demand for safe dairy products emphasizes the importance of an integrated approach of ensuring food safety throughout the entire dairy production chain"from grass to glass"-including the importance of the farm level in supplying safe and good quality raw milk (EC, 2000). The role of each participant in the chain is crucial to guarantee the overall food safety level of the consumer product, and each participant relies on food safety assurance from the previous participant in the chain. For example, when regulatory standards for total bacterial count (TBC) in raw milk are met at the farm level, the product quality later in the chain will be better guaranteed.

In the Netherlands, each bulk milk delivery is routinely sampled, monitored, and analyzed for composition and quality in an independent monitoring laboratory under the supervision of Netherlands Controlling Authority for Milk and Milk Products (COKZ, Leusden, the Netherlands). Payment contracts include milk content or levels of fat, protein, lactose, urea, SCC, TBC, antimicrobial drug residues, butyric acid-forming spores, freezing point depression, free fatty acids, and milk sediment. The testing frequency differs for differ- 
ent milk quality parameters: every delivery (antimicrobial drug residues), twice per month (SCC, TBC), once per month (butyric acid-forming spores, milk sediment), or twice per year (freezing point depression, free fatty acids). Farmers whose milk does not meet all these requirements are paid a lower price for their milk or can be rejected by the dairy processor, according to company or government regulations. On the other hand, farmers with a continuous supply of high quality milk are paid a bonus.

Some widely used tools for improving the quality and safety of bulk milk are quality assurance and certification programs for dairy farms to reach the desired farm performance level. These levels are set by the dairy processing industries that communicate this to the stakeholders (Meuwissen et al., 2003; Velthuis and Van Asseldonk, 2011). These programs include farm audits that assess different criteria such as the use of veterinary drugs, animal health, equipment, facilities, personnel and farm hygiene, disinfection procedures, residues, and feed and water management. A typical farm audit requires several hours of labor (including preparation, visit, and reporting phase) and costs several hundred euros.

Bulk milk monitoring and certification schemes aim to improve the quality of bulk milk. As farm audits entail costs, it is important to know if they actually help improve quality and safety parameters in bulk milk and if this effect is temporary or permanent. The commercial or economic advantages of auditing have not been measured (Dillon and Griffith, 2001) and studies into the effectiveness of auditing in food production are scarce; Albersmeier et al. (2009) compared the outcomes of various certification schemes in pork production and Sampers et al. (2010) related quality assurance measures to the presence of selected bacteria in poultry production. However, to date, the relationship between audits and their effect on specific microbial parameters has yet to be quantified. Therefore, the goal of this research is to study whether the TBC values of bulk milk change during the period before and after the dairy farm audit.

\section{MATERIALS AND METHODS}

The data were provided by Qlip NV (Leusden, the Netherlands), which is an independent Dutch organization responsible for the certification and auditing of dairy farms and testing deliveries of bulk milk to the processors. One data set contained bulk milk test results of milk deliveries to processors and another contained the results of all dairy farm audits (first audits, standard audits, and re-audits) performed from February 2006 to April 2008.

\section{Farm Audit Data}

Table 1 presents the descriptive statistics of the compound data set that consisted of 13,007 audits conducted on 12,855 farms from February 2006 to April 2008 and corresponding to 325,150 TBC values from 6 mo before an audit until 6 mo after. The complete farm audit data set is described in Velthuis and Van Asseldonk (2011). A farm audit record included 271 binary checklist items distributed among 52 categories that indicated a possible deviation (value 1 ) from the desired farm situation as defined by the Dutch dairy industry (base value 0). Only 8 checklist items were used in the model, 4 under the category of milking equipment maintenance, and 4 under the category of utility room-tank maintenance (Table 1). Additionally, other variables are included such as the dairy processing plant $(n=23)$, the number of attention points received, the auditor ( $\mathrm{n}=16$; anonymous), the day number of the year (to test seasonality), year ( $\mathrm{n}=3 ; 2006,2007$, and 2008), audit type $(\mathrm{n}=3$; standard, repeated, and first audit), and audit result ( $\mathrm{n}=3$; approved, rejected, and blocked). A standard audit is conducted every $2 \mathrm{yr}$, but is randomly planned, irrespective of any previous audit results. The repeated audit is performed when the result of the previous audit was not favorable (i.e., rejected), and a first audit is performed when the farm enters the program and is audited for the first time. A rejected farm was reported to have important deviations or received a high number of attention points, whereas approved farms were not. Furthermore, a farm is blocked if a decision has not yet been made various reasons and the final decision (i.e., approved or rejected) is pending for various additional information or actions.

\section{Bulk Milk Laboratory Result Data}

The TBC bulk milk was chosen because it is used in the dairy industry worldwide as the main indicator of raw milk quality. The TBC is used to assess the efficiency of cleaning and sanitation practices and general hygienic conditions during milk production (Gonzalo et al., 2006; Elmoslemany et al., 2009) and as a basis for payment schemes (Hutchison et al., 2005). For the production of high-quality milk, bacterial counts should be as low as possible. In Europe, the TBC for raw cow milk intended for heat-treated drinking milk at delivery should not exceed 100,000 cfu/mL (EEC, 1992).

In the Netherlands, TBC is analyzed twice a month in the milk monitoring laboratory by automatic enumeration with Bactoscan FC 150 (Foss A/S, Hillerød, Denmark) using flow cytometry, and each result is recorded as first or second fortnight. A suspension of cells 
Table 1. Description of the data set, consisting of 325,150 total bacterial count (TBC) values in relation to 13,007 audits performed in the period 2006 to 2008 on 12,855 farms

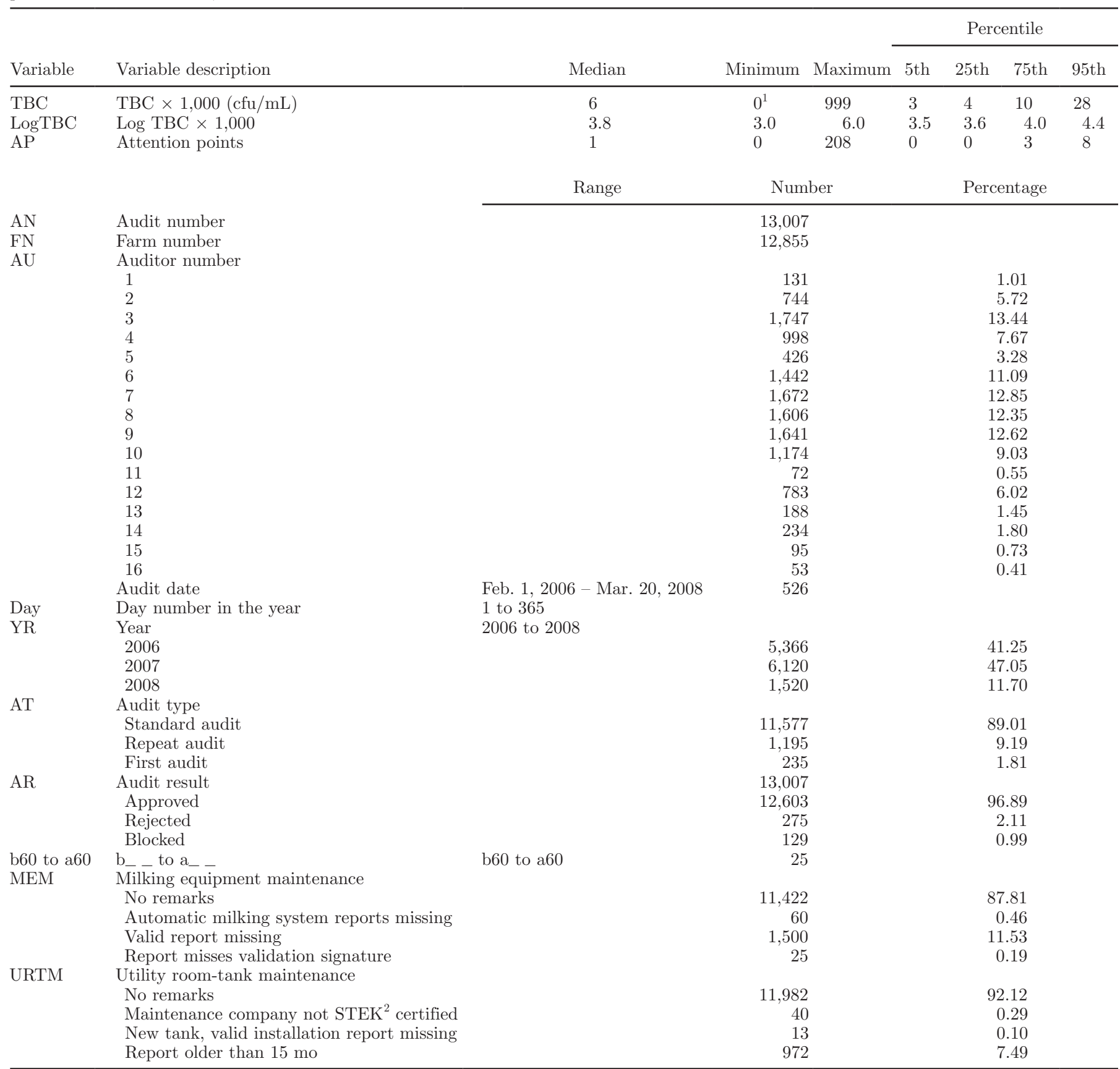

${ }^{1}$ Before transformation, the few 0 values were changed to the value 1.

${ }^{2} \mathrm{STEK}=$ Foundation for Emission Prevention in the Refrigeration, Air Conditioning and Heat Pump Industry (Baarn, the Netherlands).

is stained with a fluorogenic substrate, a high-affinity nucleic acid stain that penetrates both gram-positive and gram-negative bacteria. The liquid is passed through a narrow flow cell that is illuminated and the single passing cells are read by a fluorescence microscope in BactoScan units. This reading is converted into colony-forming units per milliliter in conformity with the reference method, SPC (ISO, 2003). Bulk milk with $\leq 20,000 \mathrm{cfu} / \mathrm{mL}$ is considered to be of good quality. The first attention level is $100,000 \mathrm{cfu} / \mathrm{mL}$ and the second is $250,000 \mathrm{cfu} / \mathrm{mL}$, as set by the milk processing companies. Typically, the milk price is reduced when TBC values exceed the second attention limit.

In this data set, the "zero" was treated as a TBC value below the detection limit. Thus, the minimum value was $1(\times 1,000 \mathrm{cfu} / \mathrm{mL})$. The maximum reported 
value was $999(\times 1,000 \mathrm{cfu} / \mathrm{mL})$ because the display technique cannot report values higher than this number. Therefore, the real maximum value may not truly be $999(\times 1,000 \mathrm{cfu} / \mathrm{mL})$. To transfer the TBC values to a linear distribution, the base 10 logarithm of $\mathrm{TBC} \times 1,000(\mathrm{cfu} / \mathrm{mL})$ was taken (i.e., $\log \boldsymbol{T} \boldsymbol{B} \boldsymbol{C})$, corresponding to a minimum of 3 and a maximum of 6 (Table 1).

To facilitate analysis, dummy variables (b60 to a60) were included that represent the time points at which the bulk milk sample was taken relative to the audit date. The letters " $b$ " and " $a$ " indicate before and after, respectively, and the numbers represent the length of the period between the TBC value and the audit date expressed in the number of months times 10. For example, a35 indicates $3.5 \mathrm{mo}$ after the audit and $b 10$ indicates 1 mo before the audit. Thus, if a TBC value was measured 3.5 mo after the audit, a35 had a value 1 and all other dummy variables had a value 0 . The dummy variables representing the period before the audit were included in the analysis to check for influences other than the audit; hence, if they significantly related to TBC values, the possible significant effect of the dummy variables after the audit might indicate another effect than the audit effect. The variable $b 00$ corresponds to the audit date, although it may not precisely match the audit date as TBC counts were recorded on a half-monthly basis and not on the exact sampling date.

\section{Statistical Analysis}

A linear mixed model was used to test the relation between the dependent variable, $\log T B C(\mathrm{cfu} / \mathrm{mL})$, and the predictor variables. The data were analyzed with Genstat version 13 for Windows (VSN International, Hemel Hempstead, UK), using the REML directive with farm in the random model to reduce the variability that may exist among farms; REML estimates the treatment effects and variance components in a linear mixed model, which consists of a linear model with both fixed and random effects. The general random mixed model is written as

$$
y=\operatorname{Random}\left(r_{i}\right)+\beta_{0}+(k 11+k 12)+\beta_{1} \cdot x_{1}+\ldots+\beta_{p} \cdot x_{p}+e,
$$

where $y=\operatorname{LogTBC} ; r_{i}=$ the random variable; $\beta_{0}=$ the constant; $k 11=\sin \frac{2 \cdot \pi \cdot \text { Day }}{365}$ and $k 12=\cos \frac{2 \cdot \pi \cdot \text { Day }}{365}$, allowing for smooth seasonality effects; $\beta_{1}=$ the estimate of the corresponding variable $x_{1} ; \beta_{p}=$ the estimate of the variable $x_{p}$; and $e=$ the error term.

First, a univariate analysis was performed to corroborate the selection and the order of the variables in the full model based on highest $P$-values. Second, all variables and interaction terms were included in the full model, and later on, each nonsignificant term $(P$ $>0.05$, Wald's test) was excluded with a backward stepwise selection procedure.

\section{RESULTS AND DISCUSSION}

The final random regression model for $\log T B C$ was as follows:

$$
\begin{aligned}
\log T B C= & \operatorname{Random}(F N+A U+Y R)+C+(k 11+k 12) \\
& +A P+A T+A R+(A T \cdot A R)+(A P \cdot A R) \\
& +M E M+U R T M+b 10+a 15+a 20+a 25 \\
& +a 30+a 35+a 40+a 45+a 50+a 55+a 60,
\end{aligned}
$$

where $F N$ is farm number, $A U$ is auditor number, $Y R$ is year, $C$ is the intercept, $A P$ is number of attention points in audit, $A T$ is audit type, $A R$ is audit result, $M E M$ is milking equipment status, and URTM is status of utility room tank maintenance. The estimates and standard errors for the variables can be found in Table 2.

We observed a significant $(P<0.001)$ decrease in 10 subsequent $\log T B C$ values during a period from 1.5 mo to at least 6 mo after the audit (a15 to a60; Figure 1), whereas no significant effect was found in the month following the audit (a05 and a10). The reason for this delay could be that the farmers receive the results of the audit (attention points and audit result) 3 to 6 wk after the audit. This may stimulate the farmers to improve management by focusing on those areas that received attention points, which may consequently decrease TBC values. Moreover, when the farm, by the time of the audit, has not undergone the required maintenance of the milking equipment and tanks, the farmer will be reminded during the audit and will be given a period of 2 wk to have the maintenance done. The maintenance of the milking equipment and tank has a decreasing effect on TBC values.

A single value of $\log T B C 1$ mo before audit (b10) was significantly higher $(P<0.05)$. This difference cannot be explained by, for example, the fact that the farmer received a notice that the farm was going to be audited only 2 to $5 \mathrm{~d}$ before the audit.

The effects of various variables on $\log T B C$ values (Table 2) were found to be statistically significant. The effects, however, were small and would not be measurable if it concerned single microbiological examinations. In this respect, the differences in $\log T B C$ values do not fulfill the definition of a biologically relevant effect, as proposed by EFSA (2011) to be "an effect consid- 
Table 2. Estimates and standard errors of the variables in the final random mixed model for $\log _{10}$ total bacterial count (LogTBC)

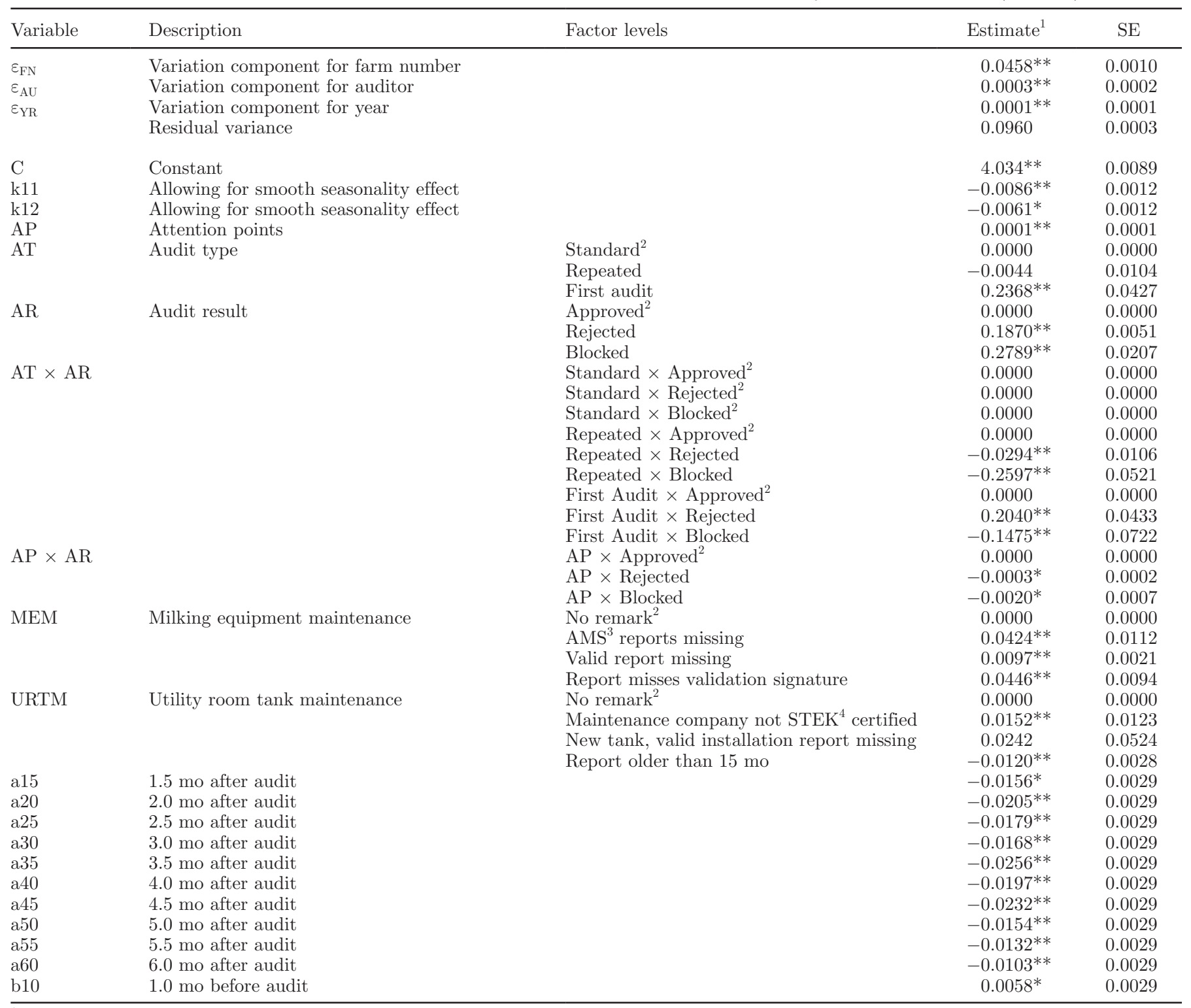

${ }^{1}$ Model coefficient.

${ }^{2}$ Reference level.

${ }^{3} \mathrm{AMS}=$ automated milking system.

${ }^{4}$ STEK $=$ Foundation for Emission Prevention in the Refrigeration, Air Conditioning and Heat Pump Industry (Baarn, the Netherlands).

${ }^{*} P<0.05,{ }^{* *} P<0.001$.

ered by expert judgment as important and meaningful for human, animal, plant, or environmental health." However, the average $\log T B C$ is the average of a very large number of individual measurements and the logtransformation reduces the scale. The TBC value in Figure 1 decreased from $7.3 \times 10^{3}$ to $6.9 \times 10^{3} \mathrm{cfu} / \mathrm{mL}$. This implies that the average number of bacteria was $6 \%$ lower after auditing than before.

The percentage decrease may even be higher if the arithmetic mean (average of the counts, not log counts) were considered. According to Rahman (1968), the arithmetic mean $(\bar{C})$ relates to the more common geometric mean $(\overline{\log C}$, mean of $\log$ values $)$ according to the following equation:

$$
\log (\bar{C})=\overline{\log C}+0.5 \cdot \ln 10 \cdot \sigma_{\log C}^{2},
$$

where $\sigma_{\log C}^{2}$ is the variance of the $\log$ counts of the samples. This implies that the arithmetic mean is af- 


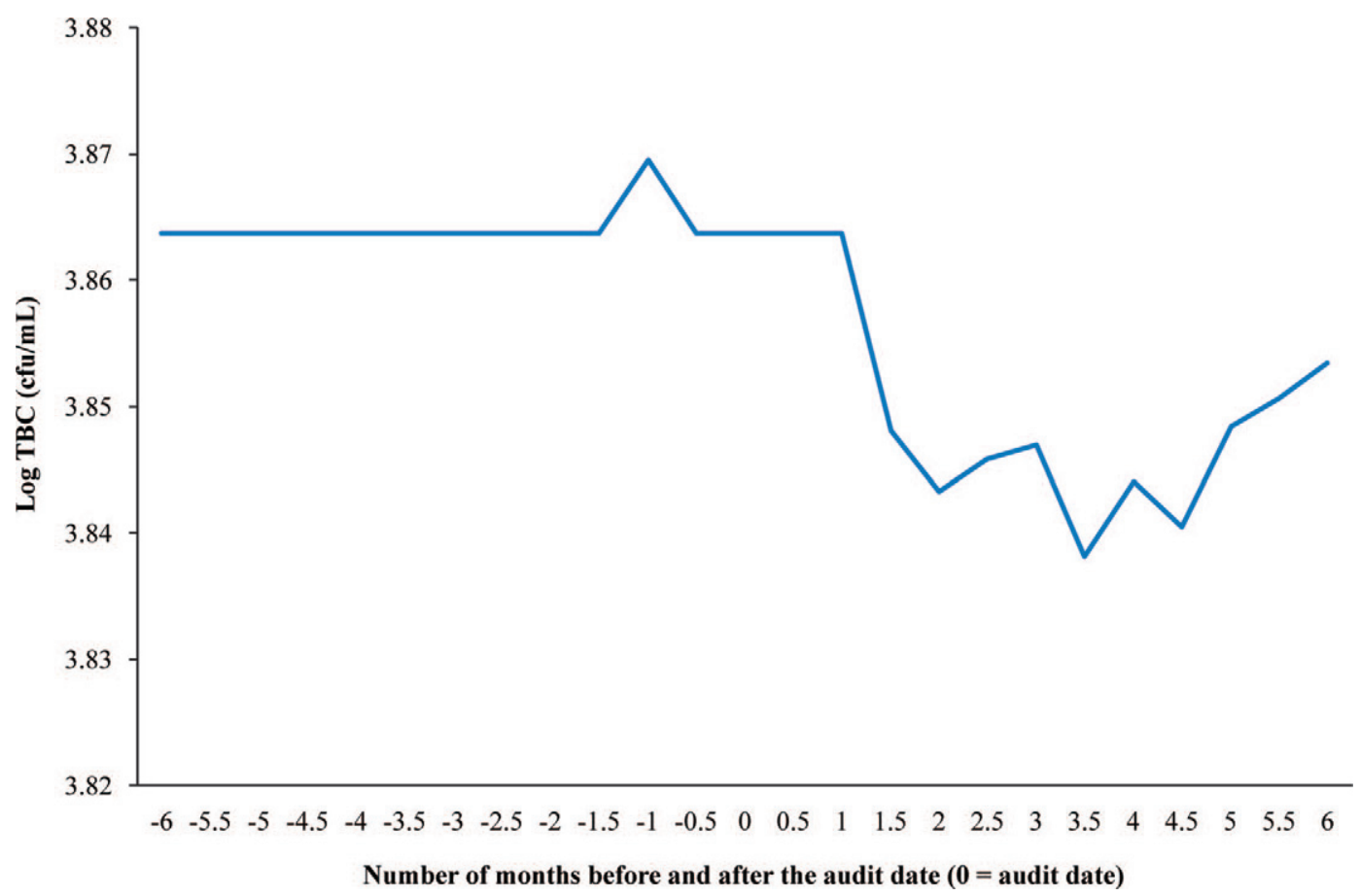

Figure 1. Weighted average of $\log T B C$ (base 10 logarithm of $T B C \times 1,000 \mathrm{cfu} / \mathrm{mL}$ ) values of all farms centered around the audit date. TBC $=$ total bacterial count. Color version available in the online PDF.

fected by both the geometric mean and the standard deviation. Assuming that TBC values are comparable to plate counts, more detailed research into the distributions and standard deviations of the TBC data would be useful to determine whether auditing diminishes the number of outliers in the distribution; that is, the extremes of $\log T B C$ values.

As can be seen in Table 2 and Figure 2, among the audit types, the standard and repeated audits were associated with the lowest average $\log T B C$ values, whereas the first audit was associated with the highest values.

The audit results of standard and repeated audits were significantly $(P<0.001)$ related to $\log T B C$ values (Figure 2). The rejected farms overall had higher values (0.19) than approved farms but slightly lower average $\log T B C$ values (0.04) in repeated audits. Furthermore, blocked farms overall had higher (0.28) average $\log T B C$ values than approved farms, but lower $(0.23)$ values than approved farms in repeated audits. One could speculate that both rejected and blocked farms improve during the time frame between an audit and the repeated audit.

The maintenance checklist categories (milking equipment maintenance and utility room-tank maintenance) had a significant effect on $\log T B C$ values. Farms that had no deviations on either of the 2 checklist categories (i.e., the desired farm situation) had the lowest average $\log T B C$ values. The results indicate that if the maintenance report of the automatic milking equipment is missing or if the maintenance report of the standard milking equipment is not validated, high $\log T B C$ values (both $3.92 \log \mathrm{cfu} / \mathrm{mL}$ ) can be expected. This is even more than not having a valid maintenance report for the standard milking equipment (i.e., $3.88 \log \mathrm{cfu} / \mathrm{mL}$ ).

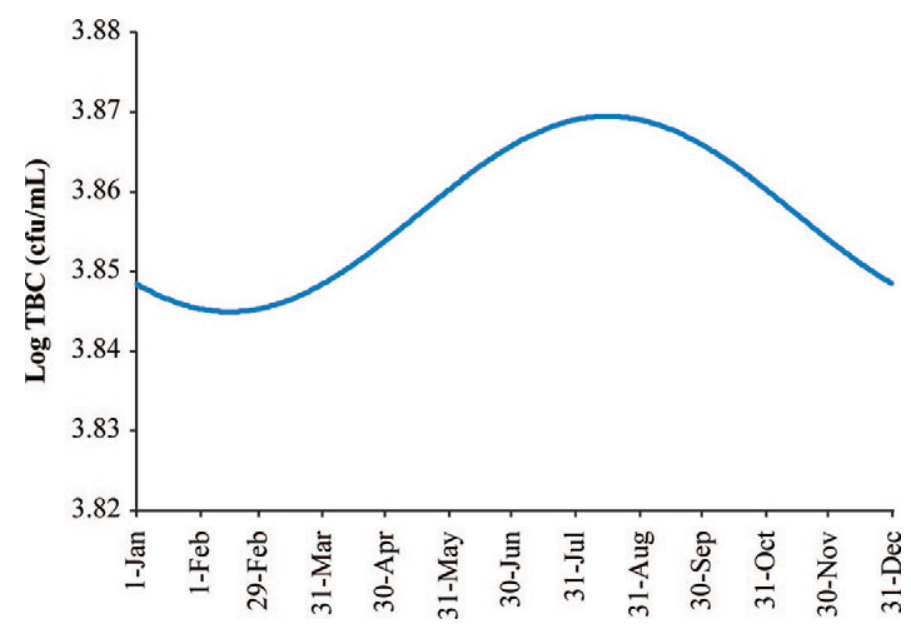

Figure 2. Seasonality effect on the weighted average $\log T B C$ (base 10 logarithm of TBC $\times 1,000 \mathrm{cfu} / \mathrm{mL}$ ) values throughout the year. $\mathrm{TBC}=$ total bacterial count. Color version available in the online PDF. 
The high $\log T B C$ values related to reports where a validation signature was missing could be explained by a possible equipment (especially vacuum) failure, which may lead to cow health problems and consequently may increase $\log T B C$ values.

If the maintenance company is not certified, increased $\log T B C$ values (i.e., on average, $3.86 \log \mathrm{cfu} /$ $\mathrm{mL}$ ) can be expected. A possible reason why the utility room-tank maintenance checklist category has an effect on $\log T B C$ values may be that the audit reminds the farmer to do tank maintenance. When the report is older than $15 \mathrm{mo}$, the average $\log T B C$ had the lowest value (i.e., on average $3.83 \log \mathrm{cfu} / \mathrm{mL}$ ). This suggests that having a report, even if it is old, is better than having none at all and better than the maintenance company not being certified.

The adequate maintenance of the milking equipment plays an important role in bulk milk quality. This could be supported by Velthuis and Van Asseldonk (2011), in which one of the most influential audit variables for TBC was the number of attention points given to milking equipment in general. The physical condition of rubber parts in the milking equipment is critical in obtaining low bacterial counts. Greater roughness of different surfaces of the milking machine equipment has been associated with insufficient cleaning procedures (CaisSokolinska and Pikul, 2008). Furthermore, scratches on the surface of milking equipment could facilitate the attachment and colonization of bacteria (Latorre et al., 2010). High vacuum fluctuations provoke changes in teat thickness (Hamann et al., 1993) and when this happens in the teat cup liner, it might aid the entrance of bacteria. The malfunctioning of pulsators, by reverse flow of milk or by allowing the flow of air against the teats, may contaminate the teats (Brandsma, 1981). The incorrect functioning of milking equipment may increase the likelihood of mastitis (Edmondson, 2001), and commonly encountered mastitis-causing organisms Staphylococcus aureus, Escherichia coli, Streptococcus agalactiae, Streptococcus dysgalactiae, and Streptococcus uberis can elevate bacterial counts in milk (Hutchison et al., 2005). Improper cooling and prolonged storage of milk could influence TBC values by increasing the microbial growth rate (Elmoslemany et al., 2009). Milk must be cooled quickly to below $4^{\circ} \mathrm{C}$ to ensure that bacteria do not multiply. According to Velthuis and Van Asseldonk (2011), poor management of the utility room, among other factors, is related to increased TBC values.

Figure 3 represents the seasonality effect of $\log T B C$, where the maximum $\log T B C$ values corresponded to mid-August (3.87 log cfu/mL) and the minimum values to mid-February $(3.84 \mathrm{log} \mathrm{cfu} / \mathrm{mL})$. One reason for the $\log T B C$ values to increase in the warmer months is that bacterial counts are higher as milk temperature increases. According to the Royal Netherlands Meteorological Institute, the highest temperature in the Netherlands is measured between July and August and the lowest between January and February. This corresponds to the maximum and minimum $\log T B C$ values found in the current study.

The seasonality behavior of $\mathrm{TBC}$ values found in this study differs from a study conducted on Irish dairy herds from 1994 to 2004 (Berry et al., 2006). In our study, the maximum $\log T B C$ values correspond to mid-August and the minimums to mid-February, whereas TBC values were highest during winter and early spring in the Irish study, a finding attributed to the dairy production system in Ireland. Cows are more likely to be exposed to microorganisms and soiled materials when housed compared with when they are grazing outdoors, increasing the probability of higher TBC values in bulk milk. Dirty teats and udders are considered one of the main sources of environmental bacteria in milk (Elmoslemany et al., 2009). Bacterial numbers in milk can vary in different seasons, because significant seasonal differences exist between cattle cleanliness when entering the milking parlor and cleaning effectiveness (Hutchison et al., 2005). The SCC increases with stage of lactation (Haenlein, 2002), which is correlated to TBC values (Gonzalo et al., 2006; Koop et al., 2009). Additionally, the health of the herd must be taken into consideration, because mastitis-causing organisms may increase SCC and TBC values (Hutchison et al., 2005; Koop et al., 2009).

The effect of the attention points on the $\log T B C$ value was -0.0004 for every given audit point for approved farms; however, we observed an interaction with the audit result. If an approved farm received 100 points, the expected $\log T B C$ value would be $3.87 \log$ $\mathrm{cfu} / \mathrm{mL}$ compared with $3.85 \mathrm{log} \mathrm{cfu} / \mathrm{mL}$ if no points were received. The finding that the number of attention points had an increasing effect on $\log T B C$ is reasonable because farm hygiene, cleanliness, cattle, equipment and facilities management, which are part of the audit checklists, are all related to TBC levels of raw bulk milk.

\section{DISCUSSION}

In this analysis, TBC was chosen to indicate the hygiene level for bulk milk; however, other microbiological markers may have similar performance levels, such as SCC, Enterobacteriaceae or coliform counts, psychrotroph count, total aerobic count, and preliminary incubation count (Hutchison et al., 2005; Elmoslemany et al., 2009). Total bacterial count was reported to have superior performance as a hygiene marker (Hutchison et 


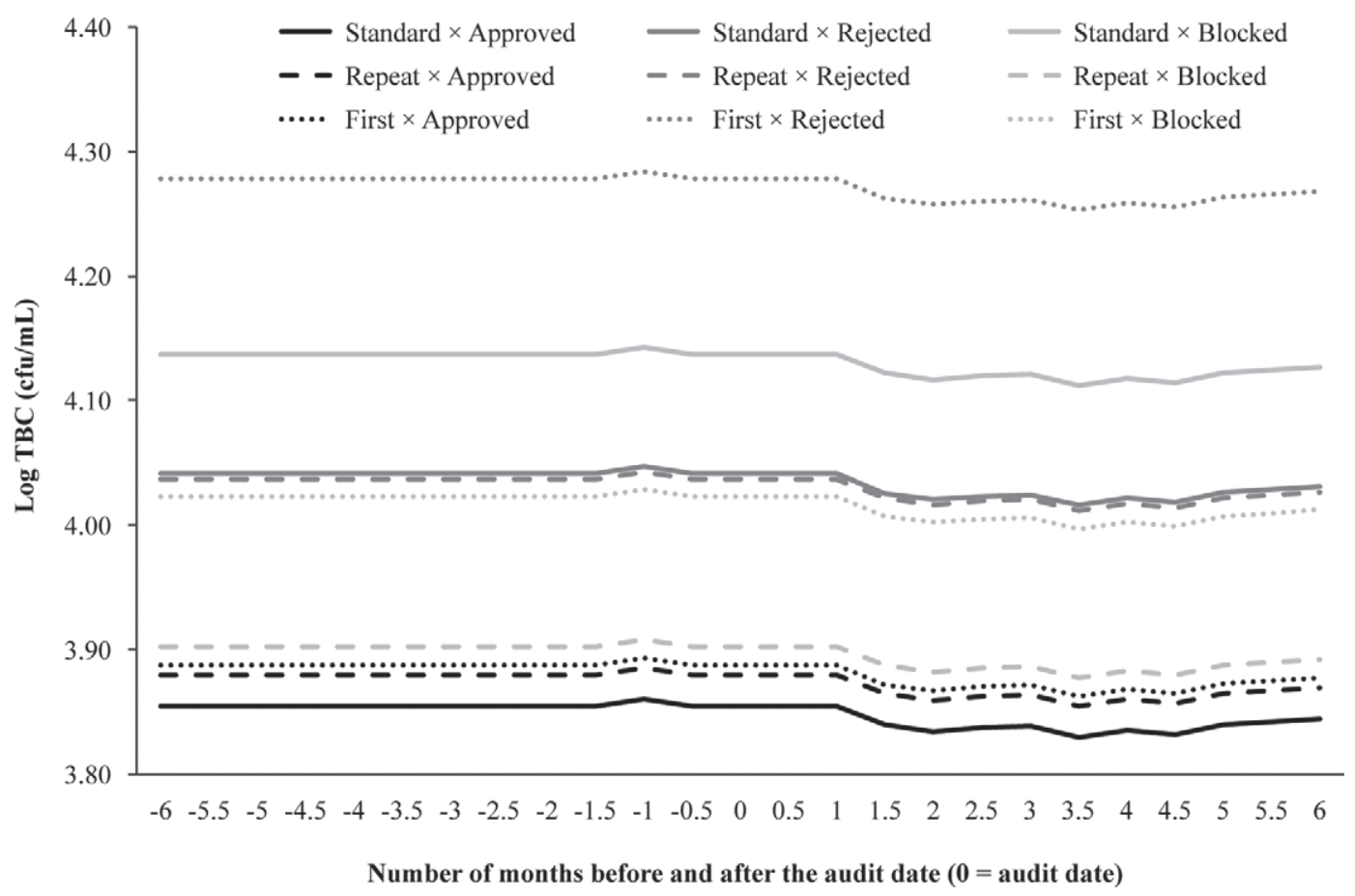

Figure 3. Estimated $\log T B C$ (base 10 logarithm of $\mathrm{TBC} \times 1,000 \mathrm{cfu} / \mathrm{mL}$ ) values for different audit types and audit results centered around the audit date. $\mathrm{TBC}=$ total bacterial count.

al., 2005). The increase in TBC correlates with unsanitary conditions associated with unclean udders before milking; poor teat sanitation, cleaning and sanitation of milking equipment, and cooling of milk (Jayarao et al., 2004; Berry et al., 2006; Pantoja et al., 2009); and poor cattle management (dirty cattle cubicles, dirty feed storage; Velthuis and Van Asseldonk, 2011). Some factors that influence TBC and the types of bacteria present in raw milk are the health and hygiene of the animal, farming and milking environment, housing and management practices, cleaning and sanitizing procedures of the milking and storage equipment, as well as the storage temperature and time (Berry et al., 2006; Elmoslemany et al., 2009). Insufficient cleanliness and sanitation of milking machines and cooling tanks are important causes of high bacterial counts (CQM, 2010). Some important factors related to bulk milk quality indicators such as TBC are udder hygiene, temperature of the washing solution, and water quality (Elmoslemany et al., 2009).

In checklist auditing, certifiers use a checklist to schematically monitor certain quality performance elements, and it has been argued that no attention is paid to the particular characteristics and conditions of the industrial sectors (Albersmeier et al., 2009). The audit is carried out based on a formal point-by-point checklist, where the auditors are able to prove that they have conducted the audit appropriately by checking the boxes on the checklist, without any incentive to unveil material deficiencies. This may be technically correct, but important quality risks can go unnoticed because they are not specifically mentioned on the checklist of technical requirements. When microbiological results were compared with government dairy hygiene inspector audits in the United Kingdom, in some cases no correlation between TBC in milk and the farm audit scores was seen (Hutchison et al., 2005). Although this way of auditing may have some drawbacks, checklists are often perceived as useful tools (Albersmeier et al., 2009).

Few studies have evaluated the reliability of thirdparty certification as a quality indicator. Some recent papers can be found in environmental management, health care, or sustainability studies, but studies regarding food safety and quality are scarce. The current study is unique because it contains extensive information on farm audits, as well as the laboratory results of bulk milk test results (Velthuis and Van Asseldonk, 2011). To the best of our knowledge, no other studies have reported the validity of audits on bulk milk quality. The focus of this investigation was on the temporary effect of auditing on a milk quality parameter; a long-term effect should be considered.

Dairy farm auditing is associated with bulk milk quality: if dairy farms have an overall negative assessment, TBC values are more likely to be inferior. 
Auditing dairy farms provides additional, but limited, information on bulk milk quality.

\section{CONCLUSIONS}

We conclude that dairy farm auditing and TBC values of bulk milk are associated positively, meaning that TBC values decrease after the date of an audit. Moreover, if dairy farms have an overall negative audit assessment, the TBC values of bulk milk are likely to be higher than average.

\section{ACKNOWLEDGMENTS}

The authors express their gratitude to Qlip NV (Leusden, the Netherlands) for providing data, to Johan Tippe and Jules Rojer (both from Qlip NV) for their assistance and discussions, and to Jan Ramakers (Qlip, Zutphen, the Netherlands) for his support on technical matters.

\section{REFERENCES}

Albersmeier, F., G. Jahn, and A. Spiller. 2009. The reliability of thirdparty certification in the food chain: From checklists to risk-oriented auditing. Food Contr. 20:927-935.

Berry, D. P., B. O'Brien, E. J. O'Callaghan, K. O. Sullivan, and W. J. Meaney. 2006. Temporal trends in bulk tank somatic cell count and total bacterial count in Irish dairy herds during the past decade. J. Dairy Sci. 89:4083-4093.

Boor, K. J. 2001. ADSA Foundation Scholar Award: Fluid dairy product quality and safety: Looking to the future. J. Dairy Sci. $84: 1-11$.

Brandsma, S. 1981. (The milking machine as a factor in udder health (author's transl.). Tijdschr. Diergeneeskd. 106:508-514.

Cais-Sokolinska, D., and J. Pikul. 2008. Evaluation of steel surface cleanliness level in dairies using the bioluminescence method. Bull. Vet. Inst. Pulawy 52:625-629.

CQM. 2010. Canadian Quality Milk On-Farm Food Safety Program. Accessed Oct. 8, 2013. http://www.dairyfarmers.ca.

Dillon, M., and C. Griffith. 2001. How to HACCP: A Management Guide. 3rd ed. ed. M. D. Associates, Grimsby, UK.

EC (European Commission). 2000. White Paper on Food Safety. COM (99) 719 final, 12 January 2000.52. Accessed Jan. 24, 2013. http:// ec.europa.eu/dgs/health_consumer/library/pub/pub06_en.pdf.

Edmondson, P. 2001. Influence of milking machines on mastitis. In Pract. 23:150-159.

EEC. 1992. Council Directive 92/46/EEC in Commission Document 39L0046. European Economic Community (EEC), Brussels, Belgium.

EFSA (European Food Safety Authority). 2010. The Community Summary Report on trends and sources of zoonoses, zoonotic agents and food-borne outbreaks in the European Union in 2008. EFSA J. 8:1496-1906.

EFSA (European Food Safety Authority). 2011. Statistical significance and biological relevance. EFSA J. 9:2372-2389.

Elmoslemany, A. M., G. P. Keefe, I. R. Dohoo, and B. M. Jayarao. 2009. Risk factors for bacteriological quality of bulk tank milk in Prince Edward Island dairy herds. Part 2: Bacteria count-specific risk factors. J. Dairy Sci. 92:2644-2652.

Gonzalo, C., J. A. Carriedo, E. Beneitez, M. T. Juárez, L. F. De La Fuente, and F. San Primitivo. 2006. Short communication: Bulk tank total bacterial count in dairy sheep: Factors of variation and relationship with somatic cell count. J. Dairy Sci. 89:549-552.

Haenlein, G. F. W. 2002. Relationship of somatic cell counts in goat milk to mastitis and productivity. Small Rumin. Res. 45:163-178.

Hamann, J., G. A. Mein, and S. Wetzel. 1993. Teat tissue reactions to milking: Effects of vacuum level. J. Dairy Sci. 76:1040-1046.

Hutchison, M. L., D. J. I. Thomas, A. Moore, D. R. Jackson, and I. Ohnstad. 2005. An evaluation of raw milk microorganisms as markers of on-farm hygiene practices related to milking. J. Food Prot. 68:764-772.

ISO. 2003. Microbiology of food and animal feeding stuffs - Horizontal method for the enumeration of microorganisms - Colony-count technique at $30^{\circ} \mathrm{C}$. ISO 4833:2003. International Organization for Standardization (ISO), Geneva, Switzerland.

Jayarao, B. M., S. R. Pillai, A. A. Sawant, D. R. Wolfgang, and N. V. Hegde. 2004. Guidelines for monitoring bulk tank milk somatic cell and bacterial counts. J. Dairy Sci. 87:3561-3573.

Koop, G., M. Nielen, and T. van Werven. 2009. Bulk milk somatic cell counts are related to bulk milk total bacterial counts and several herd-level risk factors in dairy goats. J. Dairy Sci. 92:4355-4364.

Latorre, A. A., J. S. Van Kessel, J. S. Karns, M. J. Zurakowski, A. K. Pradhan, K. J. Boor, B. M. Jayarao, B. A. Houser, C. S. Daugherty, and Y. H. Schukken. 2010. Biofilm in milking equipment on a dairy farm as a potential source of bulk tank milk contamination with Listeria monocytogenes. J. Dairy Sci. 93:2792-2802.

Meuwissen, M. P. M., A. G. J. Velthuis, H. Hogeveen, and R. B. M. Huirne. 2003. Traceability and certification in meat supply chains. J. Agribus. 21:167-181.

Noordhuizen, J. P. T. M., and J. H. M. Metz. 2005. Quality control on dairy farms with emphasis on public health, food safety, animal health and welfare. Livest. Prod. Sci. 94:51-59.

Pantoja, J. C. F., D. J. Reinemann, and P. L. Ruegg. 2009. Associations among milk quality indicators in raw bulk milk. J. Dairy Sci. 92:4978-4987.

Rahman, N. A. 1968. A Course in Theoretical Statistics. Griffin, London, UK.

Sampers, I., L. Jacxsens, P. A. Luning, W. J. Marcelis, A. Dumoulin, and M. Uyttendaele. 2010. Performance of food safety management systems in poultry meat preparation processing plants in relation to Campylobacter spp. contamination. J. Food Prot. $73: 1447-1457$.

Velthuis, A. G. J., M. Meuwissen, and R. B. M. Huirne. 2009. Distribution of direct recall costs along the milk chain. Agribusiness 25:466-479.

Velthuis, A. G. J., and M. A. P. M. Van Asseldonk. 2011. Process audits versus product quality monitoring of bulk milk. J. Dairy Sci. $94: 235-249$.

WHO. 2008. Melamine-Contaminated Powdered Infant Formula in China. World Health Organization, Geneva, Switzerland. 